\title{
Perceived Discrimination and Superior Frontal Cortex Surface Area in Children: Sex Differences
}

\author{
Assari S 1,2* \\ ${ }^{1}$ Department of Family Medicine, Charles R Drew \\ University of Medicine and Science, Los Angeles, CA, USA \\ ${ }^{2}$ Department of Urban Public Health, Charles R Drew \\ University of Medicine and Science, Los Angeles, CA, USA \\ *Corresponding author: Shervin Assari, Department \\ of Family Medicine, Department of Urban Public Health, \\ Charles R Drew University of Medicine and Science, Los \\ Angeles, CA, USA
}

Received: September 25, 2021; Accepted: October 28, 2021; Published: November 04, 2021

\begin{abstract}
Background: Limited knowledge exists on the role of Perceived Discrimination (PD) as a social determinant and risk factor that influences children's brain development and whether this association is different for male and female children.

Aim: To examine the association between PD, the superior frontal cortex, and sex differences in a national sample of 9/10-year-old children in the US.

Methods: This cross-sectional study included 8,719 children from the Adolescent Brain Cognitive Development (ABCD) study. The exposure variable was PD, and the outcome variables were the right and left superior frontal cortex surface areas, measured using structural MRIs. Covariates included: age, family structure, parental education, household income, stressful life events, financial stress, neighborhood poverty, and neighborhood toxins/pollutants (lead, PM2.5, and $\mathrm{NO}_{2}$ ). We used a mixed-effect regression model for data analysis to adjust to the nested nature of the $A B C D$ data.
\end{abstract}

Results: There was an inverse association between PD and superior frontal cortex surface area in children. We found a statistically significant interaction between PD and the superior frontal cortex, indicating a more prominent inverse association between PD and superior frontal cortex surface area in males than females. Similar findings were observed for the right and left hemispheres.

Conclusion: High levels of PD may be a more salient determinant of superior frontal cortex surface area for male than female children. Sex may alter the relevance of high PD for the brain development of US children. More research is needed on the mechanism by which sex differences emerge in the association between PD and brain development.

Keywords: Discrimination; Stress; Race; Population groups; Sex; Children

\section{Introduction}

Perceived Discrimination (PD) is a specific type of stressor that increases the risk of a wide range of undesired mental and behavioral health outcomes [1,2] such as depression, anxiety, tobacco use, alcohol use, drug use, and suicide [3]. High PD may interfere with emotion regulation, reward processing, and cognitive control of the brain [35]. However, males and females may respond differently to PD [6,7]. While most research has shown that compared to females, males are more likely to develop undesired mental and behavioral outcomes in response to PD [8-15], some studies have shown null or opposite results [16-19]. These sex and gender differences in vulnerability to discrimination may be partially due to the different coping strategies employed by males and females to adjust to PD [20].

As a type of stressor, PD has a known association with altered brain structure and function [21], but, PD's effect on the superior frontal cortex area is less understood. The superior frontal cortex is a part of the prefrontal cortex (PFC) with major cognitive, emotional, and behavioral implications [22,23]. The superior PFC is involved in executive function, emotion regulation, decision making, and behavioral control [24-26]. We know less about the relevance of PD, as an independent risk factor of the superior frontal cortex area. Very few studies have reported the effect of PD on the superior frontal cortex while controlling for other types of stressors. We need largescale data sets that have collected data on numerous social stressors and brain structure for such studies.

Although PD has been linked to children's developmental, emotional, and functional outcomes [3], these effects may depend on sex [16-19]. That is while PD is a risk factor for several undesired mental and behavioral outcomes, males and females may respond differently when they experience PD [27-29]. Therefore, PD may have different implications for substance use, depression, and physical health outcomes in males and females [29,30].

Any study of the contribution of PD to children's brain development requires careful control of potential confounders such as stress, family Socioeconomic Status (SES), neighborhood SES, and toxins/pollutants that affect brain development in children [31]. These effects include family SES, family resources, neighborhood SES, and other social and environmental factors [32-37]. Chronic exposure to adversity such as living in low-SES families or neighborhoods interfere with a child's normal brain development [38-41]. Therefore, such factors should be controlled when studying a social and environmental factor like PD as a risk factor for child brain 
development [42-46].

PD does not occur in vacuum. Exposure to PD is commonly experienced in conjunction with other stressors and risk factors [47]. Stress, family SES, neighborhood conditions, and toxins/pollutants may confound the effects of PD on a child's developmental outcomes [48-50]. Other types of stressors and SES indicators confound the effects of PD on brain development because most of these factors correlate with stressors such as PD and at the same time have undesired effects on child brain development [38,39,41,51-53]. For families, stress, low SES, high neighborhood stress, and exposure to toxins/pollutants may co-occur, and have a joint effects on the child's development [54,55]. Consequently, we need to conduct studies that extricate the effects of PD from co-occurring stressors, toxins/ pollutants, and contextual conditions [56-58]. Therefore, we have decided to conduct this study while controlling for other potential contributing factors that may confound the effects of PD on children's brain development [55,59].

\section{Aims}

To extend the existing knowledge on the possible role of PD as a unique social determinant of 9/10-year-old children's brain development in the US, we tested the association between PD and the superior frontal cortex of children, while social, physical, and economic confounders were controlled. We also explored sex differences in the association between PD and the superior frontal cortex surface area of children. Our hypothesis is that males are more vulnerable to the effects of $\mathrm{PD}$ than females, as supported by previous work [8-15].

\section{Methods}

\section{Design}

This study is a secondary analysis of the baseline (wave 1) data (2016-2018) of the Adolescent Brain Cognitive Development (ABCD) study [60-64], a national study of children's brain development in the United States $[60,65]$.

\section{Sampling}

In the ABCD study, participants were limited to $9 / 10$-year-old children recruited from multiple cities across several states in the US. In total, $21 \mathrm{ABCD}$ centers were involved in the recruitment of participants. The primary recruitment strategy was through the school systems [66]. The overall study included 10,875 children.

\section{Eligibility}

Race. Race/ ethnicity was a categorical variable and self-identified by the parents. All participants were non-Hispanic Black. This study did not include non-Hispanic White, Hispanic, Asian, Native American, or Mixed/Other racial groups. Participants were only included when their data corresponded with our variables: cognitive function, discrimination, SES, stress, and residential history ( $\mathrm{n}=$ $1,123)$.

\section{Study variables}

\section{Confounders:}

Demographic factors: Age and sex were demographic confounders. Parental education, household income, and parental marital status were the SES control variables. Parents reported the children's ages, the child's age acting as a continuous variable, and measured in months. The sex of the child was a dichotomous variable with 1 representing males and 0 representing females.

Socioeconomic status: Household income was a nominal variable with three levels: Less than 50,000, 50,000-100,000 and 100,000+, as reported by the parent. Parental marital status was represented using 1 for married status and 0 for unmarried status. Parental education was a categorical variable with the following groupings: less than a high school degree, completed high school, college started but not completed, college completed, and postgraduate study. We also used a measure of neighborhood poverty that reflected the percent of households living under poverty in the neighborhood (derived from the zip code).

Stressful life events: Stressful life events were a categorical measurement and were evaluated using the K_SADS interview of the child. Items included (1) "A car accident in which your child or another person in the car was hurt bad enough to require medical attention," (2) "Another significant accident for which your child needed specialized and intensive medical treatment," (3) "Witnessed or caught in a fire that caused significant property damage or personal injury," (4) "Witnessed or caught in a natural disaster that caused significant property damage or personal injury," (5) "Witnessed or present during an act of terrorism (e.g., Boston marathon bombing)," (6) "Witnessed death or mass destruction in a war zone," (7) "Witnessed someone shot or stabbed in the community,"(8) "Shot, stabbed, or beaten brutally by a non-family member," (9) "Shot, stabbed, or beaten brutally by a grown up in the home,"(10) "Beaten to the point of having bruises by a grown up in the home," (11) "A non-family member threatened to kill your child," (12) "A family member threatened to kill your child," (13) "Witness the grownups in the home push, shove or hit one another," (14) "A grown up in the home touched your child in his or her privates, had your child touch their privates, or did other sexual things to your child," (15) "An adult outside your family touched your child in his or her privates, had your child touch their privates or did other sexual things to your child,"(16) "A peer forced your child to do something sexually," and (17) "Learned about the sudden unexpected death of a loved one." Response items for each item were 0 (no) or 1 (yes). Our variable was also binary, with 1 for the presence of any level of financial stress and 0 for the absence of financial stress.

Financial stress: Financial Stress was a categorical variable measured using the following items:

Subjective Family SES: Subjective family SES in this study was established as financial difficulties measured by the following seven items, with the listed options referring to the following prompt: In the past 12 months, has there been a time when you and your immediate family experienced any of the following? (1) "Needed food but could not afford to buy it or could not afford to go out to get it,"(2) "Were without telephone service because you could not afford it," (3) "Did not pay the full amount of the rent or mortgage because you could not afford it," (4) "Were evicted from your home for not paying the rent or mortgage," (5) "Had services turned off by the gas or electric company, or the oil company would not deliver oil because payments were not made," (6) "Had someone who needed to see a doctor or go to the hospital but did not go because you could not afford it," and 
(7) "Had someone who needed a dentist but could not go because you could not afford it." Responses to each item were either 0 or 1 . This variable was binary, with 1 indicating the presence of any financial stress and 0 for the absence of any financial stress.

Environmental toxins/pollutants: Based on residential history, we derived neighborhood poverty, neighborhood lead, PM2.5, and $\mathrm{NO}_{2}$ levels. These variables were continuous measurements with a higher value indicating more environmental pollutants/toxins.

\section{Primary outcome}

Superior Frontal Cortex Surface Area. The ABCD study used MRIs to measure the surface area of the cortex, including the superior frontal gyrus. This variable is treated as a continuous measurement, and a high score indicated a large surface area. For a full description of MRI protocol, harmonization, quality control, movement reduction, and brain mapping, please see this paper.

\section{Independent variable}

Perceived Discrimination. The following items were used to measure PD: (1) "How often do the following people treat you unfairly or negatively because of your ethnic background? Teachers,"

(2) "How often do the following people treat you unfairly or negatively because of your ethnic background? Other adults outside school," (3) "How often do the following people treat you unfairly or negatively because of your ethnic background? Other students," (4) "I feel that others behave in an unfair or negative way toward my ethnic group," (5) "I feel that I am not wanted in American society," (6) "I don't feel accepted by other Americans," and (7) "I feel that other Americans have something against me." Responses included 1 for almost never; 2 for rarely; 3 for sometimes; 4 for often; 5 for very often; 777 for don't know; and 999 for refused to answer. We calculated a continuous measure with a higher score indicating more PD [67].

\section{Data analysis}

We used the Data Analysis and Exploration Portal (DEAP), an interface for analyzing ABCD data based on R package. First, we ruled out multi-collinearity between our studies variables and determined that our outcome had a normal distribution. Next, we applied mixedeffects linear regression models for our multivariable models; Model 1 and Model 2 were performed in the pooled sample, and Model 3 and Model 4 were performed in females and males, respectively. Model 1 did not include an interaction term but included all the confounders. Model 2, however, did include an interaction term between sex and $\mathrm{PD}$, in addition to all the confounders. Overall, we performed four mixed-effects regression models and reported the values $b, S E, t$, and p.

\section{Ethical considerations}

This analysis was exempt from a full IRB review by Charles $\mathrm{R}$ Drew University of Medicine. The study of origin (ABCD), was approved by the Institutional Review Board (IRB) at the University of California, San Diego (UCSD). Assent and consent were received from children and their parents, respectively [65].

\section{Results}

\section{Descriptives}

Table 1 shows that 8,719 9/10-year-old children with complete data were included in the current analysis. The participants selfidentified as either female $(n=4,148 ; 47.6 \%)$ or male $(n=4,571$; $52.4 \%$ ). Males were slightly older and had larger right and left superior frontal cortex surface area. Males also reported slightly higher PD than females. Males and females did not differ in their exposure to environmental toxins, financial stress, or by race, ethnicity, family structure, and parental SES.

\section{Model fit}

Table 2 presents the fit of mixed-effects regression models. This table shows that models explained a more significant proportion of the variance of right and left superior frontal cortex surface area when confounders were included.

\section{Regression models}

Table 3 shows that overall, higher PD was associated with a smaller superior frontal cortex surface area in children, net of all confounders such as age, race, ethnicity, SES, environmental toxins, and other stressors. We found a significant interaction between PD and sex on the right superior frontal cortex surface area in children. The inverse association between PD and right superior frontal cortex surface area was steeper for male children than female children.

\section{Regression models}

Table 4 shows that overall, higher PD was associated with a smaller left superior frontal cortex surface area. This negative association between PD and left superior frontal cortex surface area was steeper in males than females.

Figure 1 shows that overall, higher PD was inversely associated with superior frontal cortex surface area. However, this association was steeper for males than females. The same pattern holds for the right and left superior frontal cortex.

\section{Discussion}

Overall, PD was inversely associated with superior frontal cortex surface area in children; however, the inverse association between higher PD and smaller superior frontal cortex surface area was more pronounced in males than in females.

In this study, high PD levels were associated with smaller right and left superior frontal cortex surface areas in children. This finding can be explained by the notion that various stressors reduce brain development and function, such as executive function, learning, memory, inhibitory control, emotion regulation, and even reward processing $[51,68,69]$. PD is even more relevant to the superior frontal cortex surface area of males than females. This finding is in line with the observation that the effects of PD and associated stressors on depression and substance use may be more prominent in males than females [8-15].

While the effects of SES, neighborhoods, stress, and pollutants were controlled, PD remains a robust correlate of superior frontal cortex surface area, particularly in male children. A comprehensive list of risk factors, including PD, should be considered a social determinant of child brain development. Furthermore, the effect of PD is particularly significant in males, which supports previous studies that have reported higher vulnerability to PD in males than females [8-15]. 
Table 1: Descriptive data.

\begin{tabular}{|c|c|c|c|c|}
\hline \multirow{3}{*}{ Level } & Overall & Female & Male & \multirow{3}{*}{$\mathbf{p}$} \\
\hline & 8719 & 4148 & 4571 & \\
\hline & Mean (SD) & Mean (SD) & Mean (SD) & \\
\hline Age (Months) & $119.12(7.51)$ & $118.91(7.49)$ & $119.30(7.52)$ & 0.015 \\
\hline Right Superior frontal Cortex Surface Area & $7,775.06(965.44)$ & $7,407.75(859.05)$ & $8,108.38(935.33)$ & $<0.001$ \\
\hline Left Superior frontal Cortex Surface Area & $8,002.79(961.65)$ & $7,619.58(851.61)$ & $8,350.54(922.91)$ & $<0.001$ \\
\hline Perceived Discrimination (1-7) & $1.19(0.42)$ & $1.15(0.37)$ & $1.22(0.45)$ & $<0.001$ \\
\hline Neighborhood Poverty & $19.88(15.26)$ & $19.97(15.14)$ & $19.80(15.38)$ & 0.606 \\
\hline Neighborhood Lead Risk & $4.90(3.07)$ & $4.90(3.06)$ & $4.90(3.07)$ & 0.919 \\
\hline Neighborhood $\mathrm{NO}_{2}$ & $2.35(1.59)$ & $2.36(1.60)$ & $2.34(1.57)$ & 0.663 \\
\hline Neighborhood PM 2.5 & $7.44(2.57)$ & $7.48(2.58)$ & $7.39(2.57)$ & 0.101 \\
\hline \multirow[t]{2}{*}{ Body Mass Index (BMI) } & $18.60(3.87)$ & $18.66(3.96)$ & $18.55(3.79)$ & 0.199 \\
\hline & n (\%) & n (\%) & n (\%) & \\
\hline \multicolumn{5}{|l|}{ Race } \\
\hline White & $5,999(68.8)$ & $2,818(67.9)$ & $3,181(69.6)$ & 0.303 \\
\hline Black & $1,123(12.9)$ & $557(13.4)$ & $566(12.4)$ & \\
\hline Asian & $189(2.2)$ & $96(2.3)$ & $93(2.0)$ & \\
\hline Other/Mixed & $1,408(16.1)$ & $677(16.3)$ & $731(16.0)$ & \\
\hline \multicolumn{5}{|l|}{ Married } \\
\hline No & $2,493(28.6)$ & $1,214(29.3)$ & $1,279(28.0)$ & 0.192 \\
\hline Yes & $6,226(71.4)$ & $2,934(70.7)$ & $3,292(72.0)$ & \\
\hline \multicolumn{5}{|l|}{ Parental Education } \\
\hline < HS Diploma & $280(3.2)$ & $136(3.3)$ & $144(3.2)$ & 0.776 \\
\hline HS Diploma/GED & $655(7.5)$ & $307(7.4)$ & $348(7.6)$ & \\
\hline Some College & $2,172(24.9)$ & $1,014(24.4)$ & 1,158 (25.3) & \\
\hline Bachelor & $2,368(27.2)$ & $1,122(27.0)$ & $1,246(27.3)$ & \\
\hline Post Graduate Degree & $3,244(37.2)$ & $1,569(37.8)$ & $1,675(36.6)$ & \\
\hline \multicolumn{5}{|l|}{ Household Income } \\
\hline$<50 K$ & $2,334(26.8)$ & $1,114(26.9)$ & $1,220(26.7)$ & 0.677 \\
\hline$\geq 50 \mathrm{~K} \&<100 \mathrm{~K}$ & $2,534(29.1)$ & $1,221(29.4)$ & $1,313(28.7)$ & \\
\hline$\geq 100 \mathrm{~K}$ & $3,851(44.2)$ & $1,813(43.7)$ & $2,038(44.6)$ & \\
\hline \multicolumn{5}{|l|}{ Hispanic } \\
\hline No & $7,110(81.5)$ & $3,396(81.9)$ & $3,714(81.3)$ & 0.473 \\
\hline Yes & 1,609 (18.5) & $752(18.1)$ & $857(18.7)$ & \\
\hline \multicolumn{5}{|l|}{ Stressful Life Events (Any) } \\
\hline No & $5,732(65.7)$ & $2,694(64.9)$ & $3,038(66.5)$ & 0.142 \\
\hline Yes & $2,987(34.3)$ & $1,454(35.1)$ & 1,533 (33.5) & \\
\hline \multicolumn{5}{|l|}{ Financial Stress (Any) } \\
\hline No & $7,021(80.5)$ & $3,374(81.3)$ & $3,647(79.8)$ & 0.071 \\
\hline Yes & 1,698 (19.5) & $774(18.7)$ & $924(20.2)$ & \\
\hline
\end{tabular}

Other than PD, a wide range of societal factors correlated with superior frontal cortex surface area in this study. Race, sex, SES, and other stressors were linked to superior frontal cortex surface area. Therefore, social and environmental risk factors cumulatively hinder children's brain development, and these harmful effects are especially strong for children raised in low SES families who experience high stress and reside in neighborhoods with pollutants. Even in the context of these risk factors, any unit increase in exposure to PD may result in additional deterioration of brain development in children.

In reality, many US children experience various adversities across multiple domains [70-72]. For example, many non-Hispanic 


\begin{tabular}{|c|c|c|c|c|}
\hline & \multicolumn{2}{|c|}{ Right } & \multicolumn{2}{|c|}{ Left } \\
\hline & $\begin{array}{c}\text { Model } 1 \\
\text { All No Interaction }\end{array}$ & $\begin{array}{c}\text { Model } 2 \\
\text { All M1 + Interaction }\end{array}$ & $\begin{array}{c}\text { Model } 1 \\
\text { All No Interaction }\end{array}$ & $\begin{array}{c}\text { Model } 2 \\
\text { All M1 + Interaction }\end{array}$ \\
\hline R-squared & 0.18968 & 0.20086 & 0.19011 & 0.2012 \\
\hline$\Delta \mathrm{R}$-squared & 0.00146 & 0.00177 & 0.14702 & 0.16036 \\
\hline
\end{tabular}

Table 3: Summary of mixed-effects regressions on the association between PD and children's right superior frontal cortex surface area.

\begin{tabular}{|c|c|c|c|c|c|c|c|c|}
\hline & \multicolumn{4}{|c|}{ Model 1} & \multicolumn{4}{|c|}{ Model 2} \\
\hline & Estimate & SE & $\mathbf{P}$ & Sig & Estimate & SE & $\mathbf{P}$ & Sig \\
\hline Perceived Discrimination (1-7) & -79.05304 & 22.13936 & 0.0003579 & $\star \star * \star$ & -20.03908 & 35.24444 & 0.5696599 & \\
\hline \multicolumn{9}{|l|}{ Race } \\
\hline White & - & & & & & & & \\
\hline Black & -386.21987 & 35.24767 & $<0.001$ & $\star * *$ & -387.39766 & 35.24965 & $<0.001$ & *** \\
\hline Asian & -405.34987 & 65.30782 & $<0.001$ & *** & -407.33014 & 65.30711 & $<0.001$ & 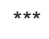 \\
\hline Other/Mixed & -143.49157 & 27.63994 & $<0.001$ & $* * *$ & -143.11902 & 27.63876 & $<0.001$ & *** \\
\hline Sex (Male) & 706.44995 & 18.27638 & $<0.001$ & 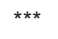 & 817.78907 & 54.88221 & $<0.001$ & *** \\
\hline Age (Month) & 2.1434 & 1.18908 & 0.0714912 & . & 2.11833 & 1.18874 & 0.0747847 & . \\
\hline Married Family & 26.73602 & 25.57244 & 0.2958204 & & 26.4756 & 25.57169 & 0.3005352 & \\
\hline \multicolumn{9}{|l|}{ Parental Education } \\
\hline \multicolumn{9}{|l|}{ Less than High School } \\
\hline HS Diploma/GED & -7.52387 & 63.34861 & 0.9054608 & & -7.71594 & 63.34402 & 0.9030522 & \\
\hline Some College & 47.11017 & 58.49551 & 0.4206317 & & 46.99441 & 58.49146 & 0.4217422 & \\
\hline Bachelor & 109.24075 & 61.94113 & 0.0778307 & . & 108.0121 & 61.93959 & 0.0812241 & . \\
\hline Post Graduate Degree & 166.56452 & 62.66971 & 0.0078793 & ** & 166.46992 & 62.66573 & 0.0079107 & ** \\
\hline \multicolumn{9}{|l|}{ Household Income } \\
\hline \multicolumn{9}{|l|}{$<50 K$} \\
\hline$\geq 100 \mathrm{~K}$ & 96.63388 & 35.73591 & 0.0068621 & ** & 96.7895 & 35.73421 & 0.0067701 & ** \\
\hline$\geq 50 K \&<100 K$ & 23.42004 & 31.02664 & 0.4503676 & & 23.22221 & 31.02504 & 0.4541796 & \\
\hline Hispanic & -176.42459 & 30.43736 & $<0.001$ & 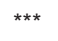 & -176.75674 & 30.43569 & $<0.001$ & *** \\
\hline Neighborhood Poverty & -2.68703 & 1.02149 & 0.0085409 & ** & -2.69903 & 1.02144 & 0.0082475 & ** \\
\hline Neighborhood Lead Risk & 10.24332 & 4.83165 & 0.0340306 & * & 10.288 & 4.83151 & 0.033253 & * \\
\hline Neighborhood $\mathrm{NO}_{2}$ & 12.73061 & 13.71072 & 0.353166 & & 13.14877 & 13.71101 & 0.3375885 & \\
\hline Neighborhood PM25 & -9.73848 & 8.56306 & 0.2554586 & & -9.68434 & 8.56269 & 0.2580896 & \\
\hline Stressful Events (Any) & -3.20034 & 19.91874 & 0.8723574 & & -3.13975 & 19.9157 & 0.8747345 & \\
\hline Financial Stress (Any) & -52.95403 & 27.06217 & 0.0504083 & . & -52.80719 & 27.06004 & 0.0510318 & . \\
\hline Body Mass Index (BMI) & 8.53665 & 2.49895 & 0.0006382 & $\star \star \star \star ~$ & 8.47067 & 2.49866 & 0.0007018 & *** \\
\hline Perceived Discrimination (1-7) × sex (Male) & & & & & -94.52963 & 43.94135 & 0.0314825 & * \\
\hline
\end{tabular}

"\# $p<0.1 ; " p<0.05 ; " * p<0.01 ; " * p<0.001$.

Black children are more likely to be a member of a low SES family, experience financial stress, reside in poor urban areas with high pollutants, and experience high levels of PD [73]. The cumulative nature of risk requires us to reduce exposures to $\mathrm{PD}$ and other risk factors in order to eliminate disparities in the brain development of all US children.

PD takes a toll on children's brain development. High levels of PD may also explain why we observe different levels of brain function and structure across socially privileged and marginalized groups. The harmful effect of PD and interpersonal racial discrimination is well known $[16,74]$. This effect asserts that group differences in brain development and cognitive performance are partly due to modifiable social factors ( $\mathrm{PD}$, stress, and pollutants) rather than genes or biological differences. These differential exposures to risk factors place low-SES and racial minorities at a relative disadvantage across multiple domains. However, to reiterate, this variation across social groups should not be attributed to fixed biological variation (i.e., 
Table 4: Summary of mixed-effects regressions on the association between PD and left superior frontal cortex surface area.

\begin{tabular}{|c|c|c|c|c|c|c|c|c|}
\hline & \multicolumn{4}{|c|}{ Model 1} & \multicolumn{4}{|c|}{ Model 2} \\
\hline & Estimate & SE & $\mathbf{P}$ & Sig & Estimate & SE & $\mathbf{P}$ & Sig \\
\hline Perceived Discrimination (1-7) & -85.85595 & 21.84397 & 8.55E-05 & $* * *$ & -33.81147 & 34.77083 & 0.3308742 & \\
\hline \multicolumn{9}{|l|}{ Race } \\
\hline \multicolumn{9}{|l|}{ White } \\
\hline Black & -398.77184 & 34.83812 & $<0.001$ & $* * *$ & -399.79429 & 34.83939 & $<0.001$ & *** \\
\hline Asian & -329.82925 & 64.52616 & $<0.001$ & $* * *$ & -331.56455 & 64.52569 & $<0.001$ & $\star * *$ \\
\hline Other/Mixed & -109.77969 & 27.31664 & $<0.001$ & $* * *$ & -109.45182 & 27.31499 & $<0.001$ & $* * *$ \\
\hline Sex (Male) & 734.43701 & 18.04318 & $<0.001$ & $* * *$ & 832.62764 & 54.15138 & $<0.001$ & $* * *$ \\
\hline Age (Month) & 1.57986 & 1.17271 & 0.1779542 & & 1.55823 & 1.17251 & 0.1838924 & \\
\hline Married Family & 36.74132 & 25.27642 & 0.1460986 & & 36.51364 & 25.27498 & 0.1485906 & \\
\hline \multicolumn{9}{|l|}{ Less than High School } \\
\hline HS Diploma/GED & -45.0198 & 62.60178 & 0.4720704 & & -45.17029 & 62.5965 & 0.4705534 & \\
\hline Some College & 4.39701 & 57.80771 & 0.939371 & & 4.29991 & 57.80293 & 0.9407024 & \\
\hline Bachelor & 58.01885 & 61.21459 & 0.3432605 & & 56.94475 & 61.21213 & 0.3522491 & \\
\hline Post Graduate Degree & 111.02641 & 61.93531 & 0.0730686 & . & 110.95803 & 61.93035 & 0.0732225 & . \\
\hline \multicolumn{9}{|l|}{ Household Income } \\
\hline \multicolumn{9}{|l|}{$<50 K$} \\
\hline$\geq 100 \mathrm{~K}$ & 88.55307 & 35.32091 & 0.0121907 & * & 88.69124 & 35.3184 & 0.0120504 & * \\
\hline$\geq 50 K \&<100 K$ & 37.57488 & 30.66448 & 0.2204745 & & 37.40882 & 30.66226 & 0.2224873 & \\
\hline Hispanic & -185.63176 & 30.09128 & $<0.001$ & $* * *$ & -185.91809 & 30.08908 & $<0.001$ & $* * *$ \\
\hline Neighborhood Poverty & -2.86265 & 1.00975 & 0.0045931 & ** & -2.87338 & 1.00968 & 0.0044402 & ** \\
\hline Neighborhood PM25 & -18.18536 & 8.50934 & 0.0326171 & * & -18.14113 & 8.50838 & 0.0330225 & * \\
\hline Stressful Events (Any) & -18.87319 & 19.67164 & 0.3373785 & & -18.82553 & 19.66916 & 0.3385387 & \\
\hline Financial Stress (Any) & -49.91857 & 26.7408 & 0.0619692 & . & -49.79166 & 26.73849 & 0.0626126 & . \\
\hline Body Mass Index (BMI) & 11.83751 & 2.46731 & $<0.001$ & $* * *$ & 11.78088 & 2.46712 & $<0.001$ & *** \\
\hline Perceived Discrimination (1-7) $\times$ sex (Male) & & & & & -83.37202 & 43.35195 & 0.05 & * \\
\hline
\end{tabular}

$\# p<0.1,{ }^{*} p<0.05,{ }^{* *} p<0.01,{ }^{* \star *} p<0.001$.

determinist view) [75].

\section{Study Limitation}

Our study had a few methodological limitations. First, given the cross-sectional design of this study, we cannot determine causal associations between PD and brain development. While we controlled for a wide range of SES indicators, other factors such as parental occupation, family wealth, physical health, psychiatric conditions, and learning disabilities were omitted confounders. Furthermore, the sample was not random, and consequently, the results are not representative or generalizable. Lastly, this study included all racial and ethnic groups, and the studied links may differ for non-Hispanic Black and White children. Therefore, future research should compare diverse racial and ethnic groups of children for the association between PD and brain development.

\section{Future Directions}

This study provides preliminary results on the association between
PD and brain development. Future research may test the additive, sub-additive, and multiplicative effects of race, ethnicity, sexual and gender minority status, and PD on brain development. Research may also test how PD changes exposure and vulnerability to other types of stress in childhood. Similar tests should also be run to explore these results in relation to other brain structures and networks. Future researchers may also use instrumental variables in order to address the problem of indigeneity and residual confounding variables.

\section{Conclusion}

Higher levels of PD are linked to lower levels of right and left superior frontal cortex surface area in 9/10-year-old children, an association that can be detected above and beyond SES, neighborhoods, stress, and environmental toxins/pollutants. The impact of PD varies between male and female children, exemplified by differences in the surface area of their respective superior frontal cortexes. High PD is more strongly associated with less superior frontal cortex surface area in male children than female children. 


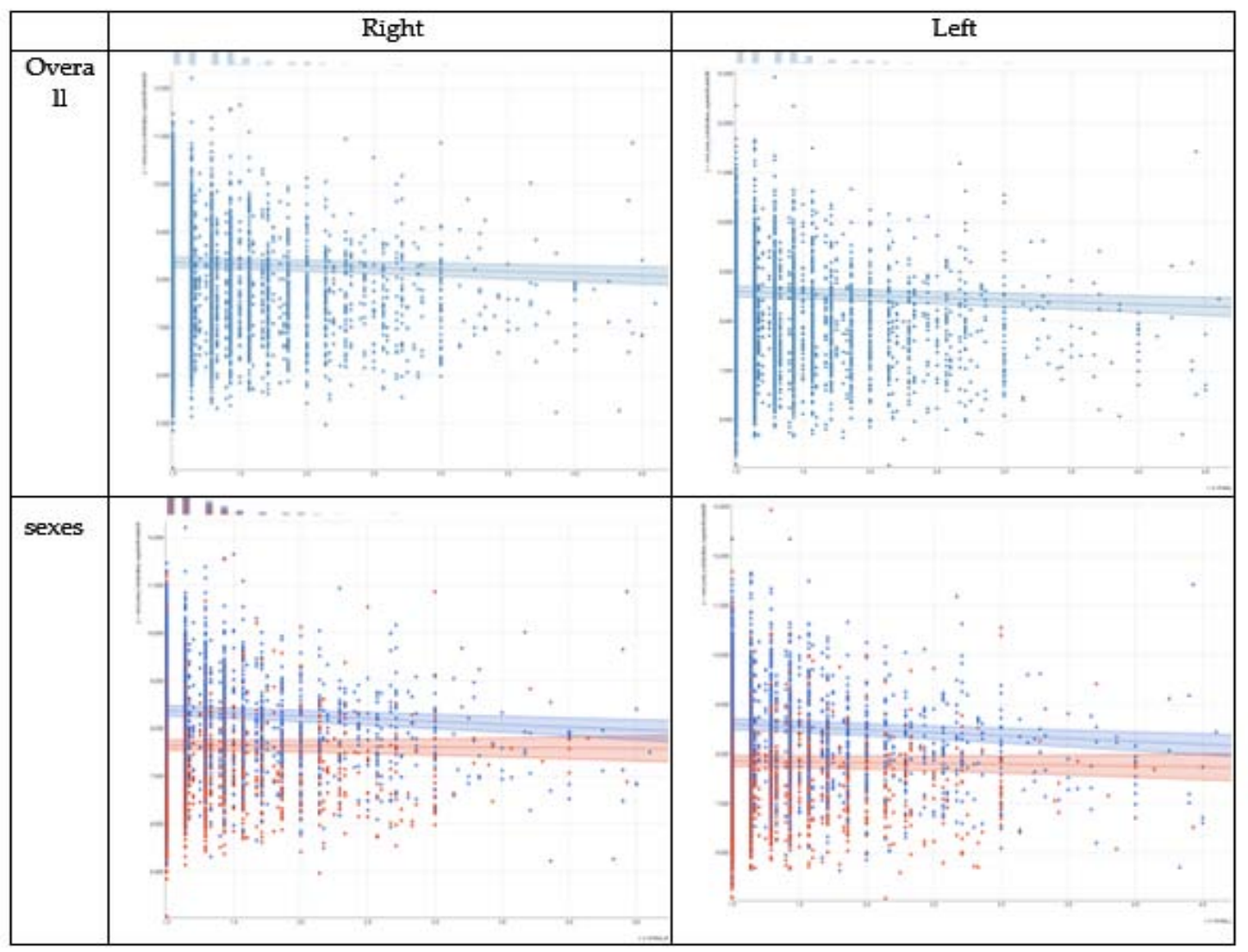

Figure 1: Association between PD and left superior frontal cortex surface area in 9/10-yr-old children.

Reducing PD (through enforcing anti-discriminatory policies) is necessary to reduce disparities in children's brain development. Particular attention should be given to males and members of social groups who commonly face discrimination (e.g., Blacks).

\section{Funding}

Data used in the preparation of this article were obtained from the Adolescent Brain Cognitive Development (ABCD) Study (https:// abcdstudy.org), held in the NIMH Data Archive (NDA). The ABCD Study is supported by the National Institutes of Health (NIH) and additional federal partners under award numbers: U01DA041022, U01DA041025, U01DA041028, U01DA041048, U01DA041089, U01DA041093, U01DA041106, U01DA041117, U01DA041120, U01DA041134, U01DA041148, U01DA041156, U01DA041174, U24DA041123, and U24DA041147. A full list of federal partners is available at https://abcdstudy.org/federal-partners.html. A listing of participating sites and a complete listing of the study investigators can be found at https://abcdstudy.org/principal-investigators.html. This manuscript reflects the views of the authors and may not reflect the opinions or views of the $\mathrm{NIH}$ or $\mathrm{ABCD}$ consortium investigators. $\mathrm{ABCD}$ consortium investigators designed and implemented the study and/or provided data but did not necessarily participate in this report's analysis or writing. The $\mathrm{ABCD}$ data repository grows and changes over time. The current paper used the Curated Annual Release 2.0, also defined in NDA Study 634 (doi: 10.15154/1503209). DEAP is a software provided by the Data Analysis and Informatics Center of
ABCD located at the UC San Diego with generous support from the National Institutes of Health and the Centers for Disease Control and Prevention under award number U24DA041123. The DEAP project information and links to its source code are available under the resource identifier RRID: SCR_016158. Shervin Assari is supported by the following National Institutes of Health $(\mathrm{NIH})$ awards: number 5S21MD000103, CA201415 02, D084526-03, U54MD007598, DA035811-05, U54MD008149, and U54CA229974.E.

\section{References}

1. Arellano-Morales L, Roesch SC, Gallo LC, Emory KT, Molina KM, Gonzalez $\mathrm{P}$, et al. Prevalence and Correlates of Perceived Ethnic Discrimination in the Hispanic Community Health Study/Study of Latinos Sociocultural Ancillary Study. Journal of Latina/o psychology. 2015; 3: 160-176.

2. Brondolo E, Beatty DL, Cubbin C, Pencille M, Saegert S, Wellington R, et al. Sociodemographic variations in self-reported racism in a community sample of blacks and latino (a) s. Journal of Applied Social Psychology 2009; 39: 407-429.

3. Mays VM, Cochran SD, Barnes NW. Race, race-based discrimination, and health outcomes among African Americans. Annu. Rev. Psychol. 2007; 58: 201-225.

4. Nagata JM, Ganson KT, Sajjad OM, Benabou SE, Bibbins-Domingo K. Prevalence of Perceived Racism and Discrimination Among US Children Aged 10 and 11 Years: The Adolescent Brain Cognitive Development (ABCD) Study. JAMA Pediatrics 2021; 175: 861-863.

5. Berger M, Sarnyai Z. "More than skin deep": stress neurobiology and mental health consequences of racial discrimination. Stress. 2015; 18: 1-10.

6. Arai M, Bursell M, Nekby L. Between meritocracy and ethnic discrimination: 
The gender difference. 2008.

7. Cogburn CD, Chavous TM, Griffin TM. School-based racial and gender discrimination among African American adolescents: Exploring gender variation in frequency and implications for adjustment. Race and social problems. 2011; 3: 25-37.

8. Assari S, Lankarani MM. Discrimination and Psychological Distress: Gende Differences among Arab Americans. Front Psychiatry. 2017; 8: 23.

9. Assari S, Lee DB, Nicklett EJ, Moghani Lankarani M, Piette JD, Aikens JE. Racial Discrimination in Health Care Is Associated with Worse Glycemic Control among Black Men but Not Black Women with Type 2 Diabetes. Front Public Health. 2017; 5: 235.

10. Assari S, Moazen-Zadeh E, Caldwell CH, Zimmerman MA. Racia Discrimination during Adolescence Predicts Mental Health Deterioration in Adulthood: Gender Differences among Blacks. Front Public Health. 2017; 5 104.

11. Assari S, Caldwell $\mathrm{CH}$. Social Determinants of Perceived Discrimination among Black Youth: Intersection of Ethnicity and Gender. Children (Basel). 2018; 5: 24 .

12. Assari S, Gibbons FX, Simons RL. Perceived Discrimination among Black Youth: An 18-Year Longitudinal Study. Behav Sci (Basel). 2018; 8: 44.

13. Assari S, Lankarani MM, Caldwell $\mathrm{CH}$. Does Discrimination Explain High Risk of Depression among High-Income African American Men? Behav Sci (Basel). 2018; 8: 40.

14. Assari S, Mistry R, Caldwell $\mathrm{CH}$. Perceived Discrimination and Substance Use among Caribbean Black Youth, Gender Differences. Brain Sci. 2018, 8: 131.

15. Assari S, Mistry R, Lee DB, Caldwell CH, Zimmerman MA. Perceived Racial Discrimination and Marijuana Use a Decade Later, Gender Differences Among Black Youth. Front Pediatr. 2019; 7: 78.

16. Assari S, Caldwell CH. Teacher Discrimination Reduces School Performance of African American Youth: Role of Gender. Brain Sci. 2018; 8: 183.

17. Assari S, Moghani Lankarani M. Workplace Racial Composition Explains High Perceived Discrimination of High Socioeconomic Status African American Men. Brain Sci. 2018; 8: 139

18. Lee DB, Peckins MK, Heinze JE, Miller AL, Assari S, Zimmerman MA. Psychological pathways from racial discrimination to cortisol in African American males and females. J Behav Med. 2018; 41: 208-220.

19. Lee DB, Peckins MK, Miller AL, Hope MO, Neblett EW, Assari S, et al. Pathways from racial discrimination to cortisol/DHEA imbalance: protective role of religious involvement. Ethn Health. 2021; 26: 413-430.

20. Banyard VL, Graham-Bermann SA. A gender analysis of theories of coping with stress. Psychology of women quarterly. 1993; 17: 303-318.

21. Meyer CS, Schreiner PJ, Lim K, Battapady H, Launer LJ. Depressive Symptomatology, Racial Discrimination Experience, and Brain Tissue Volumes Observed on Magnetic Resonance Imaging. Am J Epidemiol. 2019; 188: 656-663.

22. Ronan L, Alexander-Bloch A, Fletcher PC. Childhood obesity, cortical structure, and executive function in healthy children. Cerebral cortex. 2020; 30: $2519-2528$

23. Isaiah A, Ernst T, Cloak CC, Clark DB, Chang L. Associations between frontal lobe structure, parent-reported obstructive sleep disordered breathing and childhood behavior in the ABCD dataset. Nature communications. 2021; 12 $1-10$.

24. Chen C, Wang HL, Wu SH, Huang H, Zou JL, Chen J, et al. Abnormal Degree Centrality of Bilateral Putamen and Left Superior Frontal Gyrus in Schizophrenia with Auditory Hallucinations: A Resting-state Functional Magnetic Resonance Imaging Study. Chin Med J (Engl). 2015; 128: 31783184 .

25. Ding $Y$, Ou Y, Su Q, Pan P, Shan X, Chen J, et al. Enhanced Global-Brain Functional Connectivity in the Left Superior Frontal Gyrus as a Possible Endophenotype for Schizophrenia. Front Neurosci. 2019; 13: 145
26. Zhang S, Ide JS, Li CSR. Resting-state functional connectivity of the medial superior frontal cortex. Cerebral cortex. 2012; 22: 99-111.

27. Sutton TE, Gordon Simons L, Martin BT, Klopack ET, Gibbons FX, Beach $\mathrm{SR}$, et al. Racial discrimination as a risk factor for African American men's physical partner violence: A longitudinal test of mediators and moderators. Violence against women. 2020; 26: 164-190.

28. Gibbons FX, Stock ML. Perceived racial discrimination and health behavior: Mediation and moderation. The Oxford handbook of stigma, discrimination, and health. 2018; 355-377.

29. Brody GH, Chen YF, Murry VM, Ge X, Simons RL, Gibbons FX, et al. Perceived discrimination and the adjustment of African American youths: A five-year longitudinal analysis with contextual moderation effects. Child development. 2006; 77: 1170-1189.

30. Brondolo E, Monge A, Agosta J, Tobin JN, Cassells A, Stanton C, et al. Perceived ethnic discrimination and cigarette smoking: examining the moderating effects of race/ethnicity and gender in a sample of Black and Latino urban adults. Journal of behavioral medicine. 2015; 38: 689-700.

31. Marmot M. The Status Syndrome: How Social Standing Affects Our Health and Longevity. London: Bloomsbury Press. 2004.

32. Assari S. Parental Education on Youth Inhibitory Control in the Adolescent Brain Cognitive Development (ABCD) Study: Blacks' Diminished Returns. Brain Sci. 2020; 10: 312.

33. Assari S. Race, Ethnicity, Family Socioeconomic Status, and Children's Hippocampus Volume. Res Health Sci. 2020; 5: 25-45.

34. Assari S. Youth Social, Emotional, and Behavioral Problems in the ABCD Study: Minorities' Diminished Returns of Family Income. J Econ Public Financ. 2020; 6: 1-19

35. Assari S. Racial Variation in the Association between Suicidal History and Positive and Negative Urgency among American Children. J Educ Cult Stud. 2020; 4: 39-53

36. Assari S, Boyce S, Akhlaghipour G, Bazargan M, Caldwell CH. Reward Responsiveness in the Adolescent Brain Cognitive Development (ABCD) Study: African Americans' Diminished Returns of Parental Education. Brain Sciences. 2020; 10: 391.

37. Assari S, Boyce S, Bazargan M, Caldwell CH. African Americans' Diminished Returns of Parental Education on Adolescents' Depression and Suicide in the Adolescent Brain Cognitive Development (ABCD) Study. European Journal of Investigation in Health, Psychology and Education. 2020; 10: 656-668.

38. Manuck SB, Phillips JE, Gianaros PJ, Flory JD, Muldoon MF. Subjective socioeconomic status and presence of the metabolic syndrome in midlife community volunteers. Psychosom Med. 2010; 72: 35-45.

39. Wright CE, Steptoe A. Subjective socioeconomic position, gender and cortiso responses to waking in an elderly population. Psychoneuroendocrinology. 2005; 30: 582-590.

40. Assari S, Boyce S, Bazargan M. Subjective Family Socioeconomic Status and Adolescents' Attention: Blacks' Diminished Returns. Children. 2020; 7: 80.

41. Moon C. Subjective economic status, sex role attitudes, fertility, and mother's work. Ingu Pogon Nonjip. 1987; 7: 177-196.

42. Assari S, Moghani Lankarani $\mathrm{M}$, Caldwell $\mathrm{CH}$, Zimmerman MA. Fear of Neighborhood Violence During Adolescence Predicts Development of Obesity a Decade Later: Gender Differences Among African Americans. Arch Trauma Res. 2016; 5: e31475.

43. Assari S. Perceived Neighborhood Safety Better Predicts Risk of Mortality for Whites than Blacks. J Racial Ethn Health Disparities. 2016; 10.1007/s40615 016-0297-x.

44. Assari S, Boyce S, Caldwell CH, Bazargan M, Mincy R. Family Income and Gang Presence in the Neighborhood: Diminished Returns of Black Families. Urban Science. 2020; 4:29.

45. Assari S, Caldwell $\mathrm{CH}$. Neighborhood Safety and Major Depressive Disorde in a National Sample of Black Youth, Gender by Ethnic Differences. Children 
(Basel). 2017; 4: 14.

46. Assari S, Caldwell $\mathrm{CH}$, Zimmerman MA. Perceived Neighborhood Safety During Adolescence Predicts Subsequent Deterioration of Subjective Health Two Decades Later, Gender Differences in a Racially-Diverse Sample. Int J Prev Med. 2015; 6: 117.

47. Williams DR. Race, socioeconomic status, and health the added effects of racism and discrimination. 1999; 896: 173-188.

48. Nicksic NE, Salahuddin M, Butte NF, Hoelscher DM. Associations between Parent-Perceived Neighborhood Safety and Encouragement and Child Outdoor Physical Activity among Low-Income Children. J Phys Act Health. 2018; 15: 317-324.

49. Singh GK, Ghandour RM. Impact of neighborhood social conditions and household socioeconomic status on behavioral problems among US children. Matern Child Health J. 2012; 16: S158-169.

50. Westley T, Kaczynski AT, Stanis SAW, Besenyi GM. Parental neighborhood safety perceptions and their children's health behaviors: Associations by child age, gender and household income. Children Youth and Environments. 2013; 23: $118-147$

51. Ursache A, Noble KG, Blair C. Socioeconomic Status, Subjective Social Status, and Perceived Stress: Associations with Stress Physiology and Executive Functioning. Behav Med. 2015; 41: 145-154.

52. Senn TE, Walsh JL, Carey MP. The mediating roles of perceived stress and health behaviors in the relation between objective, subjective, and neighborhood socioeconomic status and perceived health. Ann Behav Med. 2014; 48: 215-224.

53. Feldman PJ, Steptoe A. How neighborhoods and physical functioning are related: the roles of neighborhood socioeconomic status, perceived neighborhood strain, and individual health risk factors. Ann Behav Med. 2004; 27: 91-99.

54. Assari S, Smith JL, Saqib M, Bazargan M. Binge Drinking among Economically Disadvantaged African American Older Adults with Diabetes. Behav Sci (Basel). 2019; 9: 97.

55. Assari S, Smith J, Mistry R, Farokhnia M, Bazargan M. Substance Use among Economically Disadvantaged African American Older Adults, Objective and Subjective Socioeconomic Status. Int J Environ Res Public Health. 2019; 16 : 1826.

56. Link BG, Phelan J. The social shaping of health and smoking. Drug Alcohol Depend. 2009; 104: S6-10.

57. Phelan JC, Link BG, Diez-Roux A, Kawachi I, Levin B. "Fundamental causes" of social inequalities in mortality: a test of the theory. J Health Soc Behav. 2004; 45: 265-285.

58. Link BG, Phelan J. Social conditions as fundamental causes of disease. J Health Soc Behav. 1995; 80-94

59. Assari S, Preiser B, Lankarani MM, Caldwell CH. Subjective Socioeconomic Status Moderates the Association between Discrimination and Depression in African American Youth. Brain Sci. 2018; 8: 71

60. Alcohol Research: Current Reviews Editorial S. NIH's Adolescent Brain Cognitive Development (ABCD) Study. Alcohol Res. 2018; 39: 97.
61. Casey BJ, Cannonier T, Conley MI, Cohen AO, Barch DM, Heitzeg MM, et al. The Adolescent Brain Cognitive Development (ABCD) study: Imaging acquisition across 21 sites. Dev Cogn Neurosci. 2018; 32: 43-54.

62. Karcher NR, O'Brien KJ, Kandala S, Barch DM. Resting-State Functiona Connectivity and Psychotic-like Experiences in Childhood: Results From the Adolescent Brain Cognitive Development Study. Biol Psychiatry. 2019; 86: 7-15.

63. Lisdahl KM, Sher KJ, Conway KP, Gonzalez R, Feldstein Ewing SW, Nixon SJ.et al. Adolescent brain cognitive development $(A B C D)$ study: Overview of substance use assessment methods. Dev Cogn Neurosci. 2018; 32: 80-96.

64. Luciana M, Bjork JM, Nagel BJ, Barch DM, Gonzalez R, Nixon SJ, et al. Adolescent neurocognitive development and impacts of substance use: Overview of the adolescent brain cognitive development (ABCD) baseline neurocognition battery. Dev Cogn Neurosci. 2018; 32: 67-79.

65. Auchter AM, Hernandez Mejia M, Heyser CJ, Shilling PD, Jernigan TL, Brown $S A$, et al. A description of the $A B C D$ organizational structure and communication framework. Dev Cogn Neurosci. 2018; 32: 8-15.

66. Garavan H, Bartsch H, Conway K, Decastro A, Goldstein RZ, Heeringa S, et al. Recruiting the ABCD sample: Design considerations and procedures. Dev Cogn Neurosci. 2018; 32: 16-22.

67. Ward C. The experiences of migrant youth: A generational analysis, Department of Labour. 2008.

68. Sturge-Apple ML, Jones HR, Suor JH. When stress gets into your head: Socioeconomic risk, executive functions, and maternal sensitivity across childrearing contexts. J Fam Psychol. 2017; 31: 160-169.

69. Mance GA, Grant KE, Roberts D, Carter J, Turek C, Adam E, et al. Environmental stress and socioeconomic status: Does parent and adolescent stress influence executive functioning in urban youth? J Prev Interv Community. 2019; 47: 279-294.

70. Assari S. Parental Educational Attainment and Academic Performance of American College Students, Blacks' Diminished Returns. Journal of Health Economics and Development. 2019; 1: 21-31.

71. Assari S, Caldwell CH. Parental Educational Attainment Differentially Boosts School Performance of American Adolescents: Minorities' Diminished Returns. J Family Reprod Health. 2019; 13: 7-13.

72. Assari S. Parental Educational Attainment and Academic Performance of American College Students, Blacks' Diminished Returns. J Health Econ Dev. 2019; 1: 21-31.

73. Jefferson AL, Gibbons LE, Rentz DM, Carvalho JO, Manly J, Bennett DA, et al. A life course model of cognitive activities, socioeconomic status, education, reading ability, and cognition. J Am Geriatr Soc. 2011; 59: 1403-1411.

74. Chavous TM, Rivas-Drake D, Smalls C, Griffin T, Cogburn C. Gender matters, too: The influences of school racial discrimination and racial identity on academic engagement outcomes among African American adolescents. Developmental psychology. 2008; 44: 637-654.

75. Guthrie RV. Even the rat was white: A historical view of psychology, Pearson Education. 2004. 